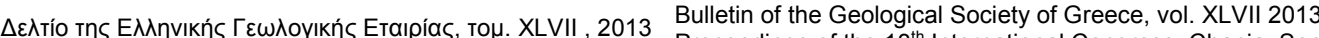
Xroceedings of the $13^{\text {th }}$ International Congress, Chania, Sept.

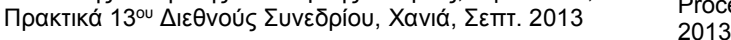

\title{
GEOELECTRIC PROSPECTING IN UNIVERSITY CAMPUS REGION FOR DETECTION OF POSSIBLE GEOLOGICAL DISCONTINUITIES, RIO, PATRA, GREECE
}

\author{
Angelis G.L. ${ }^{1}$, Stephanopoulos P. ${ }^{1}$, Papamarinopoulos St.P. ${ }^{1}$ \\ ${ }^{1}$ University of Patras, Department of Geology, Sector of Applied Geology \& Geophysics, Labora- \\ tory of Geophysics 26504 Campus, Rio Patras aggelisg@upatras.gr, stefanop@upatras.gr
}

\begin{abstract}
Geophysical prospecting is a non catastrophic technique, applicable on a wide range of problems, including archaeological, environmental and geological problems. At Campus University of Patras, a detailed geophysical investigation applied for detection of possible existing geological discontinuities, which produced serious problems at buildings and main roads of Campus. As main technique used the electric mapping and electric imaging. These were applied on already prepared geophysical grids by measuring parallel profiles along and perpendicular to the geomagnetic north. The two geophysical grids were separated 100 meters away each other. Firstly, an electric mapping procedure took place by using twin-probe array with four electrodes in distance between 0.5-3 meters. As result was the recording of soil resistance on horizontal layer with constant depth. By processing the data through Geosoft Oasis Montaj software, the distribution of this physical property was illustrated on color scale maps. Secondly, electric imaging technique applied with twenty-five equal space electrodes along straight lines, with one meter space by using the hybrid arrangement Wenner-Schlumberger (Stephanopoulos, 2002). As result was the recording of distribution of soil apparent resistivity on a vertical layer in eight separated depths. Resistivity calculated by processing imaging data through $2 D$ mathematical algorithm based on least squares inversion (Res2Dinv). Further processing by Oasis Montaj, had as a result the production of horizontal slices (Stephanopoulos 2002) and 3D maps, where the resistivity distribution was illustrated on separated depths, in color and grey schedule format. The combined geophysical investigation with the contribution of the HVSR (Horizontal to Vertical Spectral Ratio) technique confirmed the existence of geological discontinuity.

Key words: geoelectric imaging, geoelectric mapping, HVSR technique.
\end{abstract}

\section{Пєрі́ $\eta \psi \eta$}

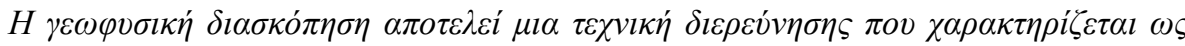

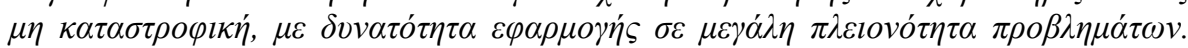

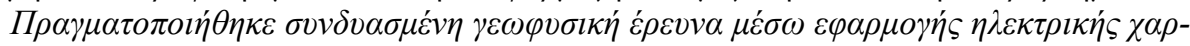

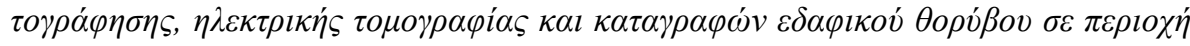

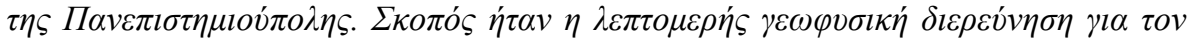

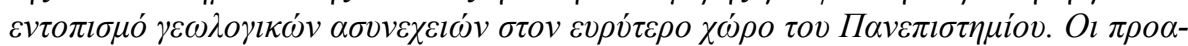

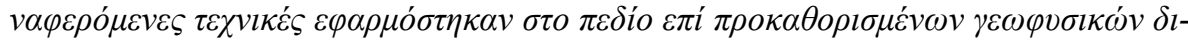

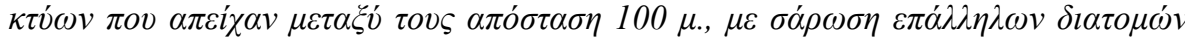

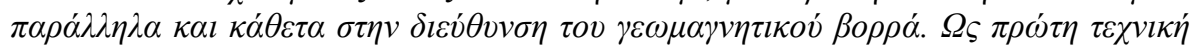

XLVII, No 3 - 1042 


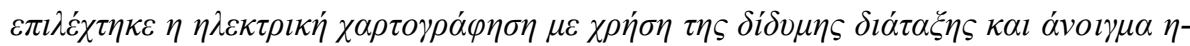

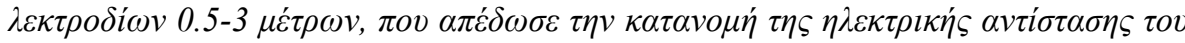

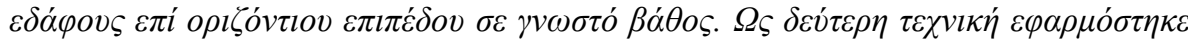

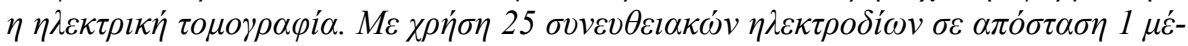

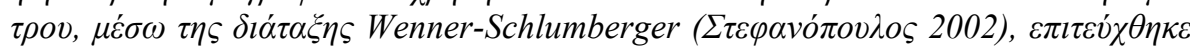

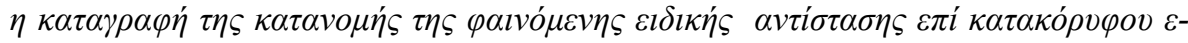

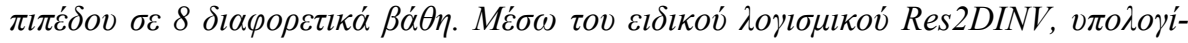

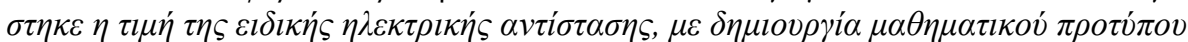

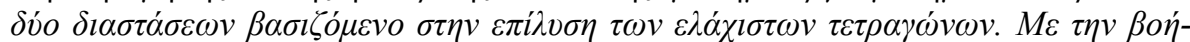

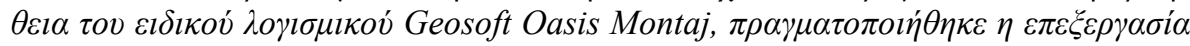

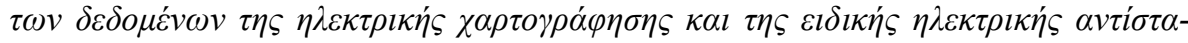

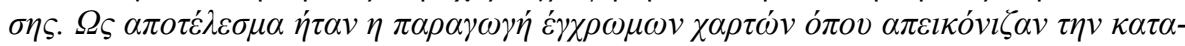

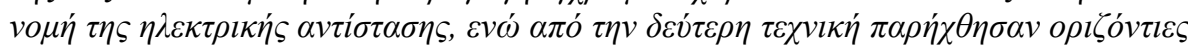

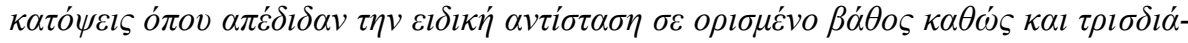

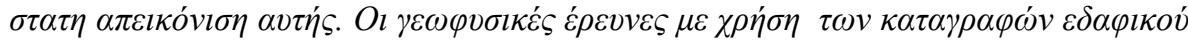

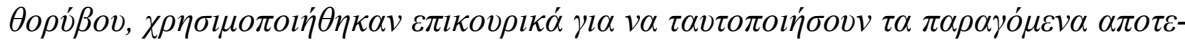

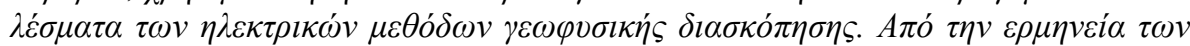

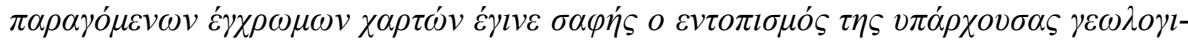

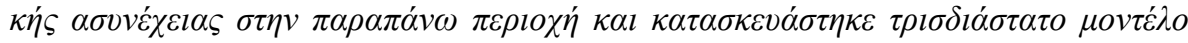

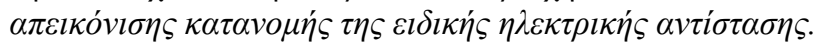

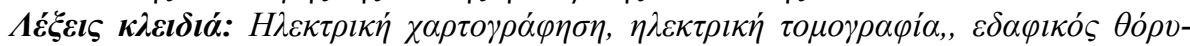
$\beta o \varsigma$.

\section{Introduction}

Geophysical prospecting techniques were based on the study of physical fields (gravitational, magnetic, electrical, seismic, electromagnetic, acoustic). Such kind of Measurements are applicable on the surface of the earth, in the air and underground (wells and shafts). The recorded information can be used to determine the location of geological structures, ore bodies, and so forth and their fundamental characteristics (Papamarinopoulos et al., 2001). All geophysical techniques are based on the use of physicomathematical principles for the development of theory. Each of them focus on a target from a different perspective, emphasized on the differential measured quantity among potential target and the surrounding soil material. These techniques are characterized by non-destructive application, as a result, they can be applicable to areas with possible archaeological targets, aquifers and subsurface geotechnical problems (Stephanopoulos, 2002). This study deals with some of electrical prospecting techniques and the application of them for exploring possible geological discontinuities (Angelis, 2013). HVSR (Horizontal to Vertical Spectral Ratio) technique was used as an assistant method to determine the dynamic characteristics of geological formations (Lane et al., 2008). The contribution of HVSR was the identification of potential geologic discontinuities (faults) in the area of Patras University plus mapping of their characteristics. The survey was conducted to oriented geophysical grids for the application of electrical mapping and electrical imaging (Zorbas et al., 2012).

\section{General Area Description}

University of Patras is located between Rio and Patras town. Inside Campus there are main and assist roads and also the students union building. One of the main problem was the damaging in students union building, where a substitution episode took place. The building abandoned for a short period. Same circumstances found on the main road of Campus, where crack impacts were easily observed on surface main road, for a long distance. Laboratory of Geophysics decided to apply a detailed geophysical research for mapping the existing geological discontinuity. The investigated area was separated in two branches. One nearby the Administration Building of

$\underline{\text { XLVII, No } 3-1043}$ 
Campus (Figure 2 left), second approximately $100 \mathrm{~m}$ away, in front the existing Campus Church (Figure 2 right). From previous geomorphology research in this area was known the existence of Rio - Patras Fault zone (Figure 1).

The Rion-Patras fault zone has a NE-SW general direction and extends along the rangefront that is found behind the large alluvial fans of the Rion-Patras coastal plain (Palyvos et al., 2007).

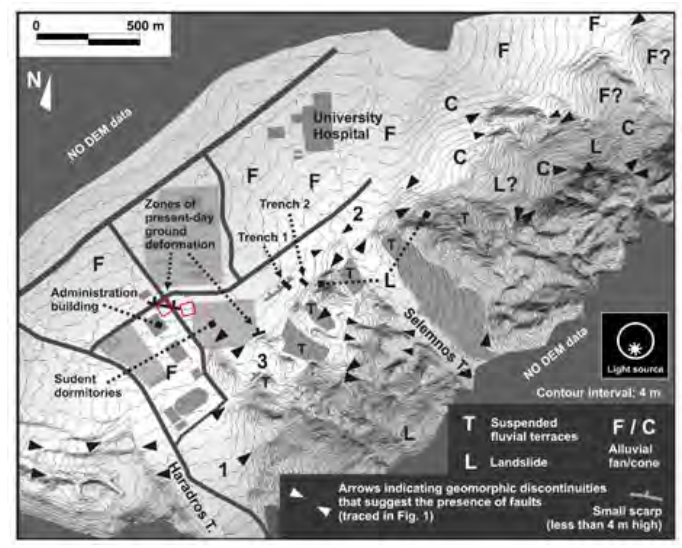

Figure 1 - Detailed morphology along part of the Rion-Patras fault zone at the longitude of the University of Patras Campus, larger geomorphic discontinuities indicative of faults are indicated by arrow heads (Palyvos $千$ et al. 2007).
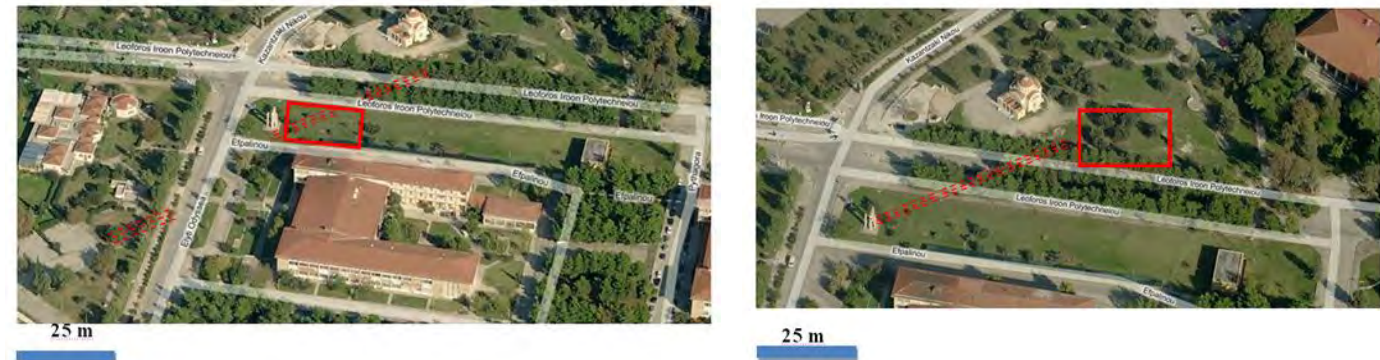

Figure 2 - Left: The boundary area of the Grass region (red square) located near Administrator building. Right: The boundary area of the Church region (red square) located between the Church and the student residence of Campus. Red lines represents the impact of geological discontinuity.

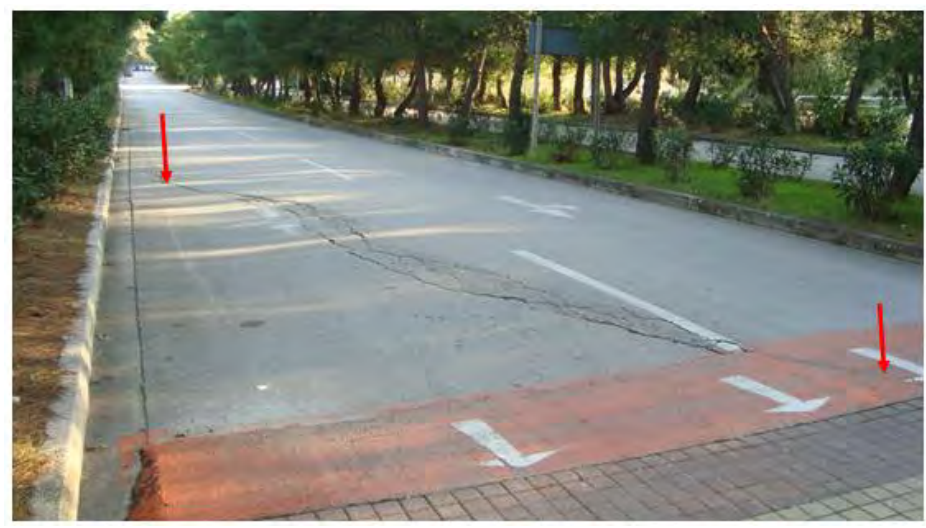

Figure 3 - Impact Crack on the main road of Campus.

$\underline{\text { XLVII, No } 3 \text { - } 1044}$ 


\section{Geology and Seismicity}

The geology of wide area in University Campus, consisted by Quaternary deposits, Pliopleistocene sedimentary rocks and unconsolidated soils. Inside are included, coastal sands, fluvial sands and gravels, Holocene deposits, weathering mantle of Plio-pleistocene sediments, as well as alluvial and diluvial deposits. In general, the total thickness of the Quaternary deposits exceeds 80 meters (Rozos et al., 2006).

The high seismicity of the area is closely related to the above mentioned fault tectonics and to existence of grabens with a recent geodynamic evolution. The dynamic loading on the various geological formations encountered in Patras area shallow and high magnitude earthquakes, apart from the direct results on the constructed environment, may also activate landslides, rockfalls, and liquefaction (Tselentis et al., 1994).

\section{Methodology}

Detailed geophysical prospecting applied on ground geophysical grids, located on two separated region, geoelectric mapping with twin-probe array through different electrode spacing, geoelectric imaging with twenty-five equal spaced electrodes through the hybrid Wenner-Schlumberger arrangement an as assistant HVSR technique. Processing of the measured data through specific software, had as result the creation of coloured maps where the distribution of measured physical property was illustrated.

\section{Geophysical Field Prospecting}

The geophysical procedure in the area of study, applied by three different techniques, geoelectric mapping, geoelectric imaging and HVSR technique.

Geoelectric mapping applied by using four electrodes with space $0.5-3 \mathrm{~m}$ distance through the twin-probe array arrangement. As a result was the recording of soil resistance on a constant depth equal to 3 times the electrode space. As main objective was the delimitation of region in high and low interest subareas, while other techniques focused on the scope of the survey, the mapping of geologic discontinuities. As main electrometer was chosen the Geoscan Rm4 and the Rateu system.

Beside the Administration building, was located the Grass area, where a geophysical grid with dimension $10 \times 20 \mathrm{~m}$ researched. In the second area (Church area), researched a geophysical grid with dimension $15 \times 15$.

The measured physical property was given in colour schedule map format by processing the geoeletric mapping data through the Oasis Montaj software.

\section{Geolectric Imaging}

Geoelectric imaging recorded the distribution of resistivity on a vertical layer on eight different separated depths. On the ground surface, twenty-five equal spaced electrodes were located on a straight line, with constant space equal to 1 meter. As main electrometer was chosen the Campus geopulse signal which could produced external electric field in square pulse formation with intensity 0.5 to $100 \mathrm{~mA}$. During the field procedure each measurement became by the combination of four electrode. Two external was used an current, while the two internal as potential. Between the two potential electrodes the apparent resistivity was measured by adopting the hybrid WennerSchlumberger arrangement (Stephanopoulos 2002). As result by this technique was the distribution of apparent resistivity on an inverse triangle, due to the geometric factor of the technique. On the maximum depth was located the corner of the triangle, while its base, near the ground surface. The central electrode was located on the middle distance of the profile (maximum depth), while the rest 24 electrodes were delimitation beside the central with equal space. By using

XLVII, No 3 - 1045 
this tip, the discreet ability of the technique increased. The current intensity was in low level at shallow depths, while in deeper levels increased until $20 \mathrm{~mA}$, while the number of cycles were extended from 2 to 3 . The average of measurement was set equal to one and the field error had been set to $1 \%$. In case of bad connections between electrode and surrounding soil, a little moisture of salty water was introduced in the base of electrodeby using a injection (Stephanopoulos 2002, 2009). By applying special software depth-slice (Stephanopoulos, 2002, 2009), horizontal slices were produced, while by further processing through Oasis Montaj software, the distribution of resistivity in horizontal plan view and in 3D format obtained.

In Grass area, which located beside the administration Campus building, 19 parallel profiles were researched, while in second area (Church area), 16 parallel profiles. In second area the geoelectric imaging technique applied along and perpendicular to geomagnetic north axis.

\section{HVSR Technique}

In 1989 Nakamura suggested estimating the amplification factor from the ratio of amplitude spectra of the horizontal to vertical components of ground acceleration recorded on the surface. The relation between this ratio and the frequency is called the HVSR curve and has a peak with in dominating frequencies of the recording. The peak amplitude is the amplification factor estimate, and its frequency is the principal frequency of surface layer. Furthermore, Nakamura ascertained that such a characteristic peak of the HVSR curve is strictly related to local geology, being independent of source parameters and signal frequency (Nakamura, 2000). He also indicated that the HVSR method would give the most accurate results when the spectral ratio were evaluated from the horizontal and vertical component of S wave (Nakamura et al., 2002).

\section{Geophysical Inversion}

Geophysical inversion was separated in two parts. Firstly was focused on processing the data from geoelectric mapping through the world standard software Oasis Montaj. As result was the creation of colour schedule maps where the distribution of soil resistance illustrated in Ohms. During the processing applied correction in case of base moving, while the data were extremely searched for instantly existing bad datum points.

Secondly the data from geoelctric imaging were processed by using three different software. During the measuring procedure in field, inside the data had been introduced the geometric factor of the applied electrode arrangement. The elimination of this was successful during the transformation of the data in format for Res2dinv software (Stephanopoulos, 2002). By using 2D special mathematical algorithm based on least square inversion, the calculation of resistivity in Ohms $\cdot \mathrm{m}$ was real. The depth of first level was set equal to 0.5 times the electrode spacing, while the sequence deeper depths were increased by a value of $10 \%$. The ratio of vertical to vertical filter was set equal to one and the damping factor was limited between 0.001 to 0.16 , while the ability of recalculation was enabled. The radius search was set to be applied if the rms error was not decreased about $5 \%$. Maximum number of iteration was chosen equal to 5 and the starting model was set to be scheduled by using the apparent resistivity values.

Horizontal slices from geoelectric imaging data, were produced by adopting special depth-slice software (Stefanopoulos, 2002), which had the ability to reformat the processed data in Oasis Montaj format. Horizontal slices illustrated the distribution of resistivity on constant depth, while there was the ability to be compared with results from geoelectrical mapping. Statistical analysis by using the mean value each profile, applied before the main process before 3D procedure. By adopting 3D subroutine of Oasis Montaj software, a 3D presence of resistivity values obtained.

\section{Geophysical results}

The result of geoelectric mapping in Grass area is illustrated in Figure 4.

XLVII, No $3-1046$ 


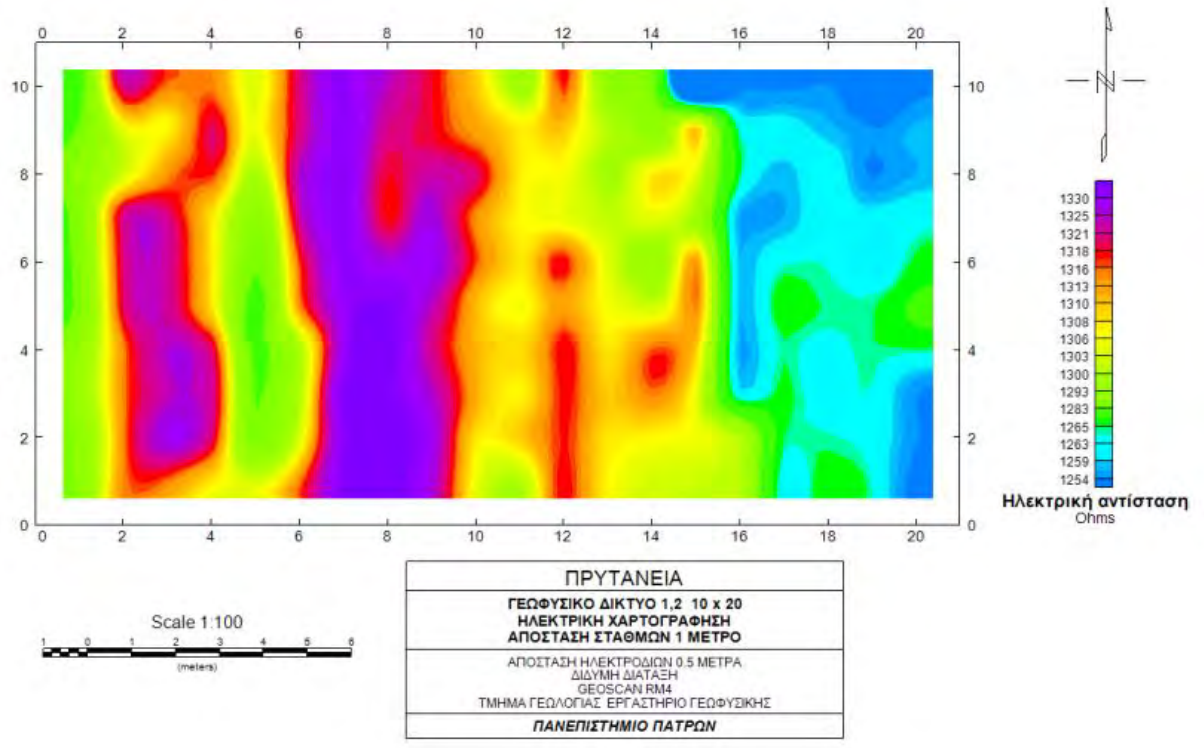

Figure 4 - Distribution of electrical resistance in Grass area by applying the Twin Probe Array (N-S).

At the west corner of the map in figure 4 there are high values of soil resistance, while in the opposite side these seemed to be decreased. The illustrated geophysical anomalies does not have any geometrical formation, while between 4 and 5 is obvious a discontinuity of geological material.

The application of geoelectric imaging illustrated in Figure 5.

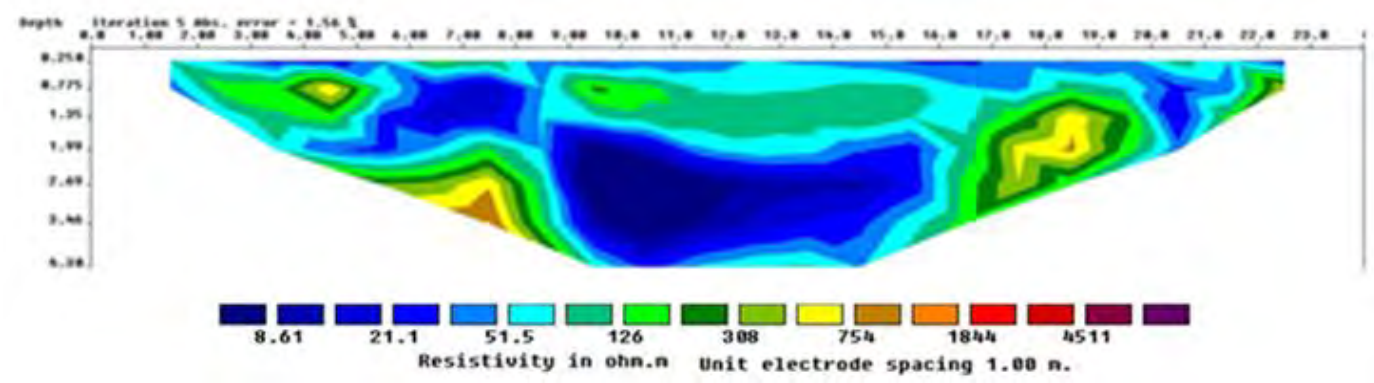

Figure 5 - Vertical electrical section of geoelectric imaging.

As it is obvious from Figure 5 the depth of investigation limits at 4.3 meters. In this section the resisitivity varies from $0.6-754 \mathrm{Ohms} \cdot \mathrm{m}$. Low values of that physical property seemed to be visible mostly on the center of the profile, while highest values are located peripheral of that. Between electrode $8 \& 9$, the transformation of the geological material is obvious by the discontinuity. By applying the depth-slice software, in collaboration with the Oasis Montaj software, the horizontal slices illustrated in Figure 6.

Figure 6 presents the distribution of resistivity in horizontal slice at approximately 1 meter depth. High resistivity values located almost on all over the illustrated map. In some cases these are given a geometric schedule, but not so clearly. On the East side of the map the geologic material have been shifted for a distance equal to $1 \mathrm{~m}$ at least, while the high resistivity values have been substituted by lower. In the centre of the map between $16-18$, there is a certificated separation of this geological material along the N-S axis.

$\underline{\text { XLVII, No } 3-1047}$ 


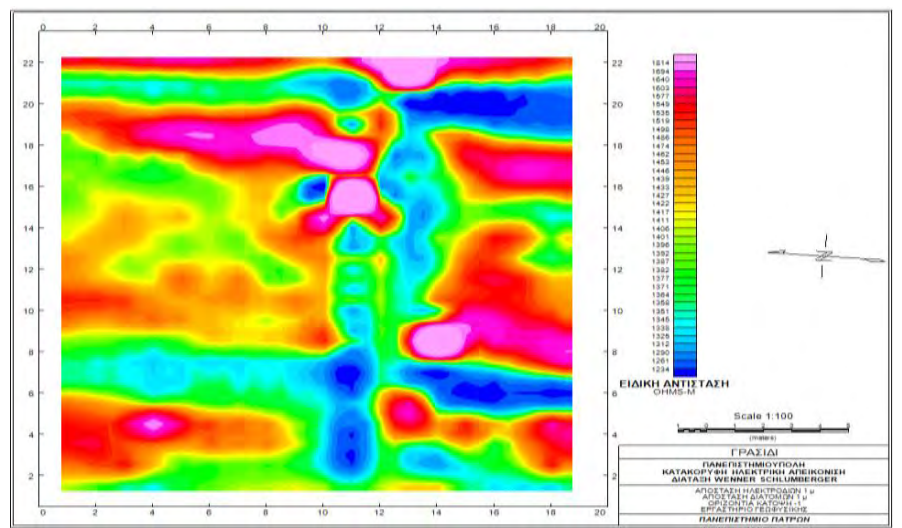

Figure 6 - Distribution of electrical resistance meter in $1 \mathrm{~m}$ depth on Grass area using the hybrid arrangement Wenner-Schlumberger with $1 \mathrm{~m}$ distance between electrodes $(\mathrm{E}-\mathrm{W})$.

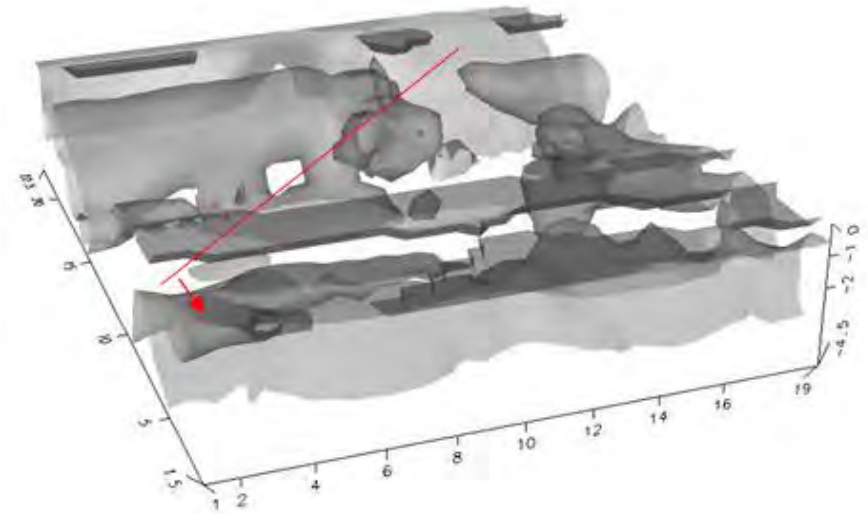

Figure 7 - 3D distribution of resistivity in $1480 \mathrm{Ohms} \cdot \mathrm{m}$ in Grass area.

Figure 7 is given the 3D distribution of resistivity in Grass area. The red arrow means the existence of metallic pipes which are using for grass watering. The red line indicates the impact of the geological discontinuity in that area (Mourelatos et al., 2012).

In Figure 8 is given the result by using the geoelectric mapping in Church area. At the left, mapping has been applied parallel to geomagnetic axis, while at the right, perpendicular to that.
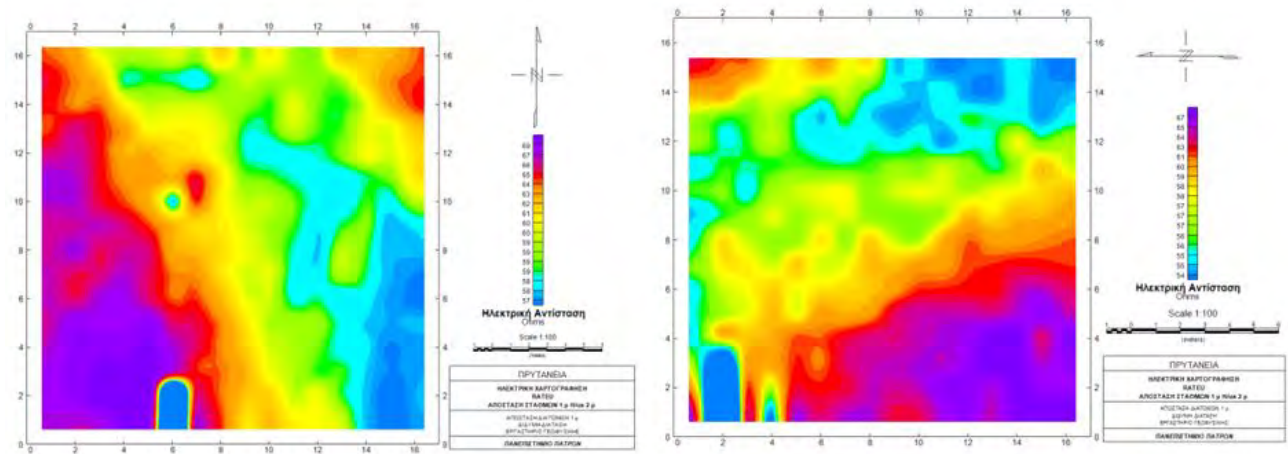

Figure 8 - Distribution of electrical resistance in Church area by applying the Twin Probe Array (N-S, E-W).

$\underline{\text { XLVII, No } 3-1048}$ 
In this region the geoelectric mapping applied with electrodes at $2 \mathrm{~m}$ distance, through twin-probe array. Both of processing gave the same result. High values of soil resistance at the top and bottom of the map, with non well geometric formation. In the middle of each map, the high resistance values separated by the existence of lower level values, while the first formation is shifted at least $1 \mathrm{~m}$ away.
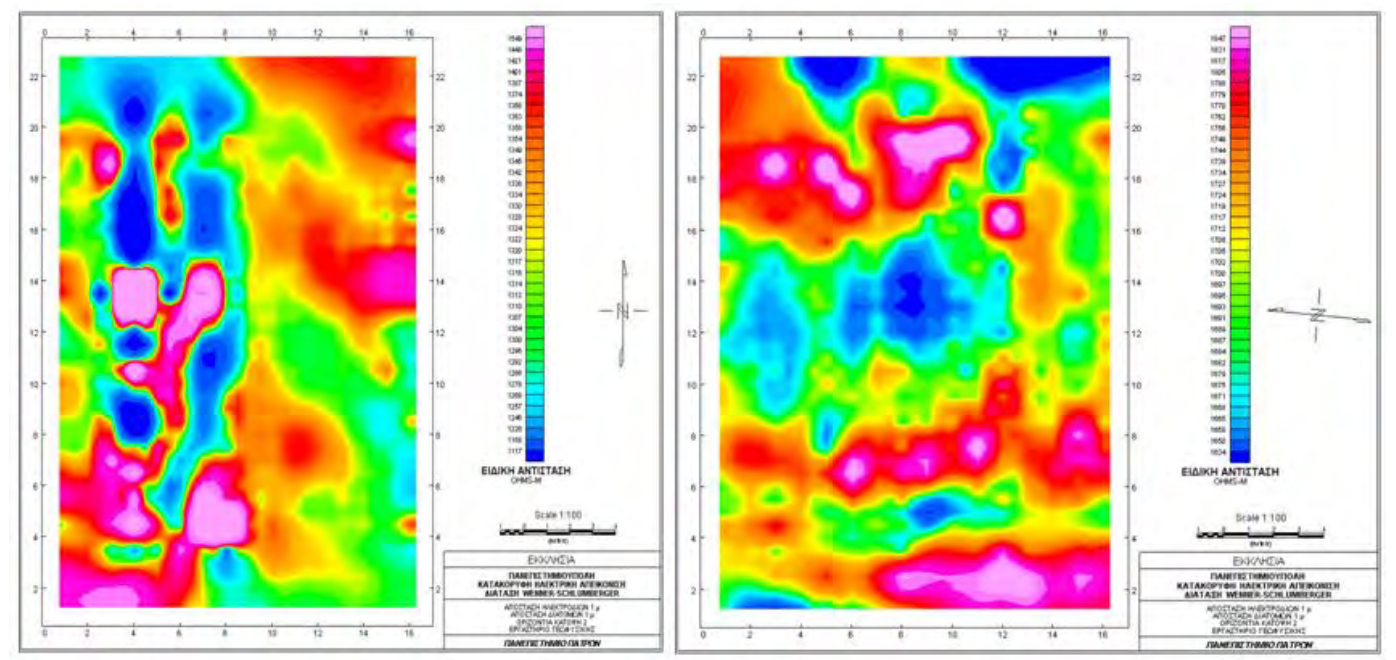

Figure 9 - Distribution of electrical resistance meter in $2 \mathrm{~m}$ depth on Church area using the hybrid arrangement Wenner-Schlumberger with $1 \mathrm{~m}$ distance between electrodes (N-S,E-W).

High values of resistivity occur almost all over in both maps, while non-well geometric formation appears. In some cases and especially in the centre and towards to the top of map a shift of geologic formations is obvious. From Figure 9 certificated that the continually of material are separated by existence of lower resistivity values.

By processing the above data set in $3 \mathrm{D}$ the result in Figure 10 produced, where the impact of possible geological discontinuity is emphasized by the red line (Mourelatos et al., 2012).

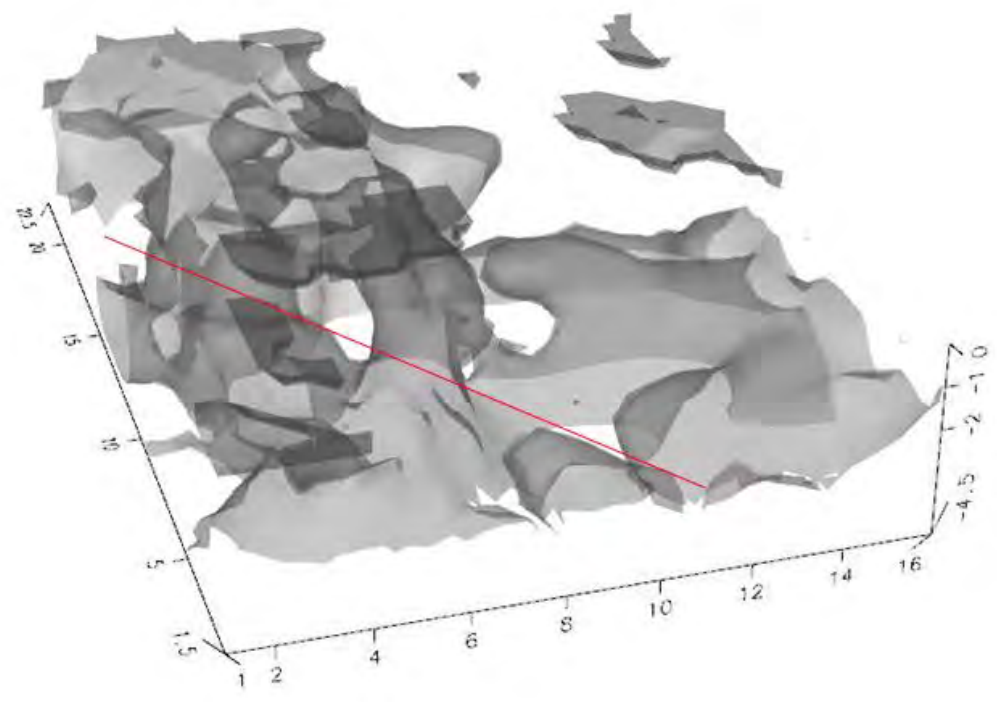

Figure 10 - 3D resistivity distribution in $1300 \mathrm{Ohms} \cdot \mathrm{m}$ in Church area.

XLVII, No $3-1049$ 


\section{Conclusion}

Detailed geophysical research in Campus of University of Patras, gave the chance for the well mapping of an existing impact of geological discontinuity. Geoelectric mapping with twin-probe array recorded the distribution of soil resistance and separated the researched region in subareas with low and high interest. Geoelectric imaging technique focused on high interest area location. By chosen the appropriate electrode space, in collaboration with suitable electrode arrangement, increased the resolution of that technique. Electric mapping gave well description of general geological statement, while imaging gave the expecting result where the existing fault was mapped. Further processing with 3D gave the chance to the observer to see details which were not seemed directly, while the underground pipe and geological discontinuity were well recorded. Also the existence of the above geological evidence was found by geomorphological prospecting which was applied by Palyvos $千$ et. al. 2007. At this point the geomorphological research is certificated by geophysical investigation. The HVSR technique, found that the geological discontinuity is extended until 50 meters depth. That depth couldn't be reached by geoelectric imaging due to the existence of physical and artificial obstacles, limited the electrode spacing.

\section{Acknowledgements}

This work is a part of the Msc Thesis "Detailed Geophysical Prospecting for the investigation of possible geological discontinuities in University Campus area of Patras, Greece".

We are grateful to the Rector and the staff of the Technical Service of the University of Patras, for giving permission to investigate in the University Campus. We warmly thank Dr. P. Paraskevopoulos for valuable ideas and discussion in the field about HVSR technique, also we would like to thank Dr. K. Nikolakopoulos, Associate Professor in Department of Geology, University of Patras for his help in the construction of 3D mapping. We also thank undergraduate students for their help in the field (P. Zorbas, E. Metaksa, M.-E. Norda, Ch. Gakou, A. Oikonomou, K. Stratopoulos, D. Tsakiris, P. Chatzileontiadis, S. Mourelatos, L. Smailis) and Mrs E. Kouzeli, Msc student.

\section{References}

Angelis G.L. 2013. Detailed Geophysical Prospecting for the investigation of possible geological discontinuities in University Campus area of Patras, Msc Thesis, Greece.

Lane J.W.Jr., White E.A., Steele G.V. and Cannia J.C. 2008. Estimation of bedrock depth using the horizontal-to-vertical (H/V) ambient-noise seismic method, in Symposium on the Application of Geophysics to Engineering and Environmental Problems, April 6-10, 2008, Philadelphia, Pennsylvania, Proceedings: Denver, Colorado, Environmental and Engineering Geophysical Society, 13.

Mourelatos S. and Smailis L. 2012. Processing of Geoelectric imaging data through 3D algorithms for the detection of existing geological discontinuation in region of University Campus, Bachelor Thesis, Lab of Geophysics, Department of Geology, Sector of Applied Geology and Geophysics, University of Patras.

Nakamura Y. 2000. Clear identification of fundamental idea of Nakamura's method for dynamic characteristics estimation of subsurface using microtremor on the ground surface, Proceedings of 12th World Conference on Earthquake Engineering, New Zealand.

Nakamura Y., Sato T. and Nishinaga M. 2002. Local site effect of Kobe based on microtremor measurement.

Palyvos N., Pantosti D., Stamatopoulos L. and De Martini P.M. 2007. Geomorphological reconnaissance of the psathopyrgos and Rion-Patras fault zones (Achaia, NW Peloponnesus), Bulletin of the Geological Society of Greece vol. XXXX.

Papamarinopoulos St. and Stephanopoulos P. 2001. Laboratory notes for the course Introduction to Applied Geophysics, University of Patras, Greece.

XLVII, No 3 - 1050 
Rozos D., Koukis G. and Sabatakakis N. 2006. Large-scale engineering geological map of the Patras city wider area, Greece, IAEG paper number 241.

Stephanopoulos P. 2002. The contribution of Geophysics with geoelectric imaging in solution of Archaeological and Environmental problems, PhD Thesis, University of Patras, Department of Geology, Sector of Applied Geology \& Geophysics.

Stephanopoulos P. 2009. Geophysical hardware and software notes, Vol. I, II, University of Patras, Greece.

Tselentis G. Melis N. and Sokos E. 1994. The Patras (July 14, 1993; Ms=5.4) earthquake sequence, Proc. Of the $7^{\text {th }}$ Congress of the Geol. Society of Greece.

Zorbas P., Metaxa Ev., Norda M., Economou A., Stratopoulos K., Tsakiris D. and Chatzileodiadis P. 2012. Detailed Geophysical Research in Region of University Campus for detection of existing geological discontinuation. Bachelor Thesis, Lab of Geophysics, Department of Geology, Sector of Applied Geology and Geophysics University of Patras. 